\title{
Effects of the Variation in Brain Tissue Mechanical Properties on the Intracranial Response of a 6-Year-Old Child
}

\author{
Shihai Cui, ${ }^{1,2}$ Haiyan Li, ${ }^{1,2}$ Xiangnan Li, ${ }^{3}$ and Jesse Ruan ${ }^{1,2}$ \\ ${ }^{1}$ Tianjin University of Science and Technology, Tianjin 300222, China \\ ${ }^{2}$ Tianjin Key Laboratory of Integrated Design and On-line Monitoring for Light Industry \& Food Machinery and Equipment, \\ Tianjin 300222, China \\ ${ }^{3}$ Shanghai HAIMA Automobile R\&D Co., Ltd., Shanghai 201201, China
}

Correspondence should be addressed to Shihai Cui; shihaicui@tust.edu.cn

Received 8 March 2015; Revised 29 April 2015; Accepted 14 June 2015

Academic Editor: Feng Zhu

Copyright (C) 2015 Shihai Cui et al. This is an open access article distributed under the Creative Commons Attribution License, which permits unrestricted use, distribution, and reproduction in any medium, provided the original work is properly cited.

Brain tissue mechanical properties are of importance to investigate child head injury using finite element (FE) method. However, these properties used in child head FE model normally vary in a large range in published literatures because of the insufficient child cadaver experiments. In this work, a head FE model with detailed anatomical structures is developed from the computed tomography (CT) data of a 6-year-old healthy child head. The effects of brain tissue mechanical properties on traumatic brain response are also analyzed by reconstruction of a head impact on engine hood according to Euro-NCAP testing regulation using FE method. The result showed that the variations of brain tissue mechanical parameters in linear viscoelastic constitutive model had different influences on the intracranial response. Furthermore, the opposite trend was obtained in the predicted shear stress and shear strain of brain tissues caused by the variations of mentioned parameters.

\section{Introduction}

The epidemiological investigations showed that the craniocerebral injury caused by traffic accidents was one of the main reasons for children's death [1]. Children head injury criteria and endurance limits are of great importance to develop head protective device. Head injury experiments using child cadavers are the most effective way to study head injury criteria and endurance limits [2]. However, the absence of child cadaver experiments largely hampers the understanding of children's craniocerebral injury mechanism in consideration of ethical morality. Recently, finite element (FE) method provides a new way to solve these problems by computational mechanics and computer technology [3-7]. Roth et al. [8] created a head FE model of a 6-month-old child including main anatomical features of the skull, tentorium, fontanels, falx, cerebrospinal fluid (CSF), and cerebrum based on computed tomography (CT) data. In this study, the FE model was used to evaluate the traumatic injury under the shaking and impact loading conditions. Roth et al. [9-11] also developed a detailed 3-year-old child head FE model to investigate child head injury criteria. Compared with a scaled adult head FE model, the result showed that it was not accurate when scaling an adult head to obtain child head. Ruan et al. [12] developed a detailed 6-year-old head FE model from CT data and conducted the validation of FE model. Cao et al. [13] further developed a detailed FE 10 -year-old head model by using ANSYS ICEM CFD and HYPERMESH code from CT data.

It is well known that the proper brain tissue material constitutive models and accurate material parameters are the key factors of FE method to investigate craniocerebral injury. However, the mechanical properties of brain tissues varied with child age gradually $[14,15]$. Furthermore, the mechanical properties used in the FE head models were mainly obtained from animal experiments or scaled data from adults due to the absence of child cadaver experiments, which limited the accuracy of FE method.

In this study, a FE model with more detail anatomical features was developed based on head FE model created by Ruan et al. [12]. The effects of brain tissue mechanical parameters variation on intracranial response were systematically 


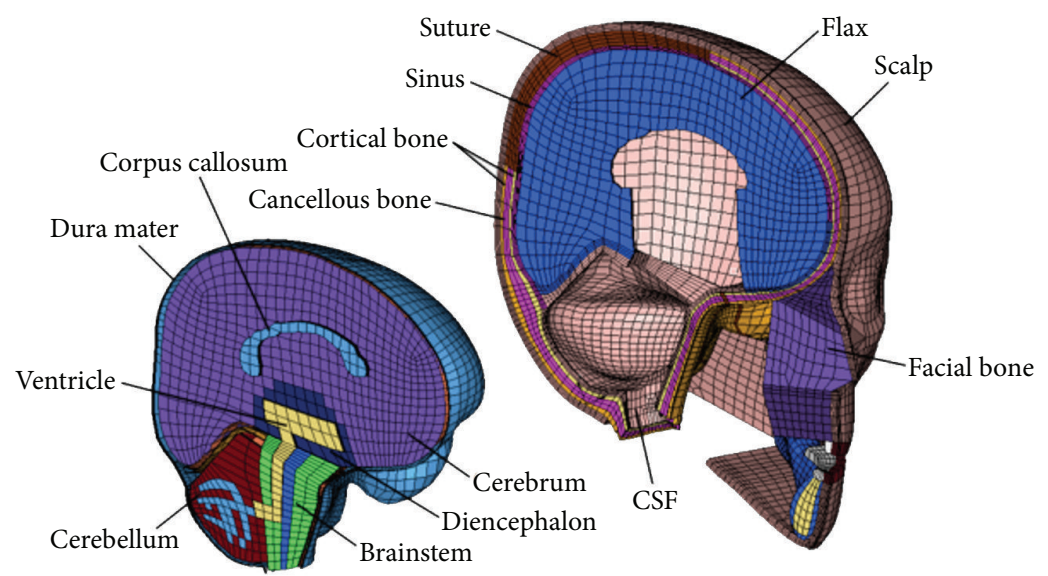

FIGURE 1: FE model of a 6-year-old child head with detailed head anatomical structures.

evaluated according to Euro-NCAP testing regulation. The craniocerebral injury mechanism for children was discussed.

\section{Methods}

2.1. FE Model Description. Based on the validated FE model created by Ruan et al. [12], intracerebral soft brain tissues were further divided, and hard tissues such as mandibular bones and facial bone were created based on the CT data of a 6-year-old child head using the FE developing method in the literature [21]. Mesh qualities of the FE model were also optimized in this study. The detailed 6-year-old child head FE model was shown in Figure 1; it can be found that the skull includes frontal bone, sphenoid bone, ethmoid bone, the outer plate and inner plate, and undergrown diploe of occipital bone, parietal bones, and temporal bones. The brain soft tissues include cerebrum, corpus callosum, cerebellum, brainstem, ventricle, diencephalon, sinus, flax, CSF, and dura mater. The whole FE head model with 103,716 nodes mainly consisted of 17,346 shells (falx, dura mater, and tentorium) and 96,128 bricks (other brain structures). The meshes among brain tissues, CSF, and skull were connected with common nodes. The developed FE model has been validated in Li's study [22] and Ruan's study [12].

2.2. Mechanical Properties of Brain Tissues. The linear viscoelastic constitutive model was commonly applied to investigate brain tissue injury in the head FE models. The Zener model for brain tissues was adopted in this research, and the constitutive equation was defined in the following equation:

$$
G(t)=G_{\infty}+\left(G_{0}-G_{\infty}\right) e^{-\beta t},
$$

where $G_{\infty}$ is the long-term shear modulus, $G_{0}$ is the shortterm shear modulus, and $\beta$ is decay coefficient.

Thibault and Margulies [14] compared the linear elastic shear modulus of cerebrum in a 3-day-old piglet (equivalent to a 1-month-old human infant) with that of 1-year-old pig (equivalent to a 4-year-old human infant) and found that the shear modulus was obviously different even at low strains. Chatelin et al. [15] found that child's brain mechanical
TABLE 1: Brain mechanical properties found in the literature and used in the simulation.

\begin{tabular}{lcccc}
\hline Literature & $G_{0}(\mathrm{kPa})$ & $G_{\infty}(\mathrm{kPa})$ & $\beta\left(\mathrm{s}^{-1}\right)$ & $K(\mathrm{MPa})$ \\
\hline Roth et al. [9] & 5.99 & 2.32 & 0.09248 & 2110 \\
Nicolle et al. [16] & 9.884 & 3.725 & 920 & 1125 \\
Shuck and Advani [17] & 49 & 16.2 & 145 & 1125 \\
Lee [18] & $26.9-110$ & 2.87 & 50 & $1.25-5.44$ \\
DiMasi et al. [19] & 34.474 & 17.23 & 100 & 68.948 \\
Ruan [20] & 528 & 168 & 35 & 127.9 \\
\hline
\end{tabular}

In the table, $K$ is bulk modulus.

properties varied evidently with age when children were younger than 2 years under low frequency shear load. The result showed that long-term and short-term shear moduli of white matter, gray matter, and brain stem of children older than 2 years were the same as those of adults. Additionally, the shear modulus of brain stem is two or three times stiffer than that of white matter and gray matter regardless of age. Thibault and Margulies [14] and Dobbing [23] found that the composition of the brain tissue of 2-year-old children, such as DNA polymerase content, water content, and lipid content, was mostly the same as those in adults $[9,11]$. The brain mechanical properties in the linear viscoelastic constitutive model reported in the literatures are summarized in Table $1[9,16-20]$. Table 2 summarizes the other head material properties used in the FE head model.

From Table 1, it can be seen that brain mechanical properties vary in a large range as reported in the literatures. As for the short-term shear models, it varies in the range of $5.99-528 \mathrm{kPa}$, while the long-term shear modulus varies in the range of $2.32-168 \mathrm{kPa}$. Decay coefficient varies in the range of $0.09248-920 \mathrm{~s}^{-1}$, and $K$ varies in the range of $1.25-$ $2110 \mathrm{MPa}$.

To evaluate the effects of brain tissue mechanical parameters variation on intracranial response, a comprehensive parametric study was conducted. The simulation matrix with different parametric combinations is shown in Table 3. The parameters reported in the literature $[9,17]$ were adopted as the baseline experiment, where the short-term shear modulus 


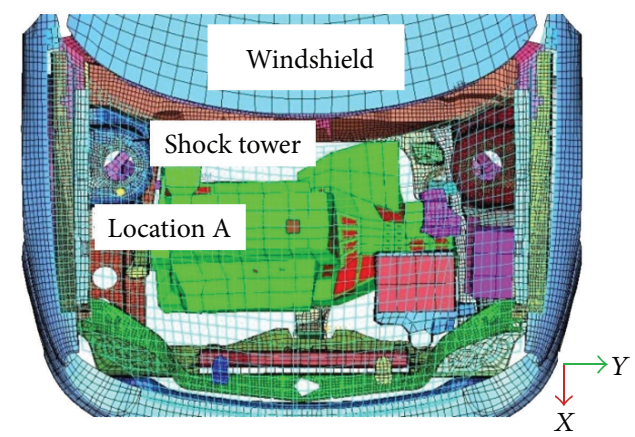

FIGURE 2: Impact location beneath the engine hood.

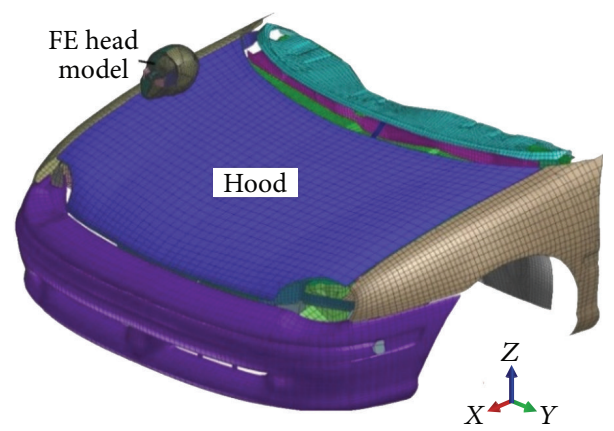

FIGURE 3: Simulation of impact between FE head model and engine hood.

TABLE 2: Material properties used in the head model.

\begin{tabular}{lccc}
\hline & Density $/ \mathrm{kg} \cdot \mathrm{m}^{-3}$ & $\begin{array}{c}\text { Poisson's } \\
\text { ratio }\end{array}$ & $E / \mathrm{MPa}$ \\
\hline Meninges & 1140 & 0.45 & 31.5 \\
CSF & 1040 & 0.49 & 0.012 \\
Scalp & 1200 & 0.42 & 16.7 \\
Cortical bone of skull & 2150 & 0.22 & 9870 \\
Cancellous bone of skull & 2150 & 0.22 & 3690 \\
Sutures & 2150 & 0.22 & 1100 \\
\hline
\end{tabular}

TABLE 3: Detailed experiment series with different parameters.

\begin{tabular}{lcccc}
\hline & $G_{0}(\mathrm{kPa})$ & $G_{\infty}(\mathrm{kPa})$ & $\beta\left(\mathrm{s}^{-1}\right)$ & $K(\mathrm{MPa})$ \\
\hline Base & 49 & 16.2 & 145 & 2190 \\
Ex_1 & 4.9 & 1.62 & 145 & 2190 \\
Ex_2 & 490 & 162 & 145 & 2190 \\
Ex_3 & 49 & 16.2 & 1.45 & 2190 \\
Ex_4 & 49 & 16.2 & 14.5 & 2190 \\
Ex_5 & 49 & 16.2 & 1450 & 2190 \\
Ex_6 & 4.9 & 1.62 & 145 & 219 \\
Ex_7 & 4.9 & 1.62 & 145 & 21.9 \\
\hline
\end{tabular}

$G_{0}$ was taken as $4.9,49$, and $490 \mathrm{kPa}$, respectively. Longterm shear modulus $G_{\infty}$ varied as $1.62,16.2$, and $162 \mathrm{kPa}$, respectively. Decay coefficient $\beta$ varied at the levels of 1.45 , $14.5,145$, and $1450 / \mathrm{s}$, and bulk modulus $K$ varied at the levels of 21.9, 219, and $2190 \mathrm{MPa}$. These values can cover all the reported data in Table 1. Particularly, the reported results showed that the bulk modulus of brain tissues was at least $10^{5}$ times than shear modulus [15]. Therefore, the proportion of bulk modulus to shear modulus in all experiment series should meet the special requirements. The experiment series in Table 3 can meet the special requirements.

2.3. Load and Boundary Setup of Impact Simulation Experiments. The impact between the developed child head model and engine hood was reconstructed according to Euro-NCAP testing regulations [24]. Engine hood surface at location A where injurious structure of shock absorber exists (Figure 2) is selected from child headform test zones as impact location [22].

Figure 3 shows the forehead of FE model impacts location A of the engine hood surface in the simulations, which were conducted by using PAM-CRASH code. The velocity of the center of mass of FE head is set at $35 \mathrm{~km} / \mathrm{h}$ and the engine hood is still. Velocity direction of FE head was 50 degrees with the horizontal plane, and impact direction was downward and rightward related to front structure on vehicle longitudinal vertical plane.

\section{Results and Discussion}

\subsection{Intracranial Response with Different $K$ Values}

3.1.1. Intracranial Pressure. Though $G_{0}, G_{\infty}$, and $\beta$ play an important role in intracranial pressure, Ex_1, Ex_6, and Ex_7 experiments in Table 3 only focus on the effect of bulk 


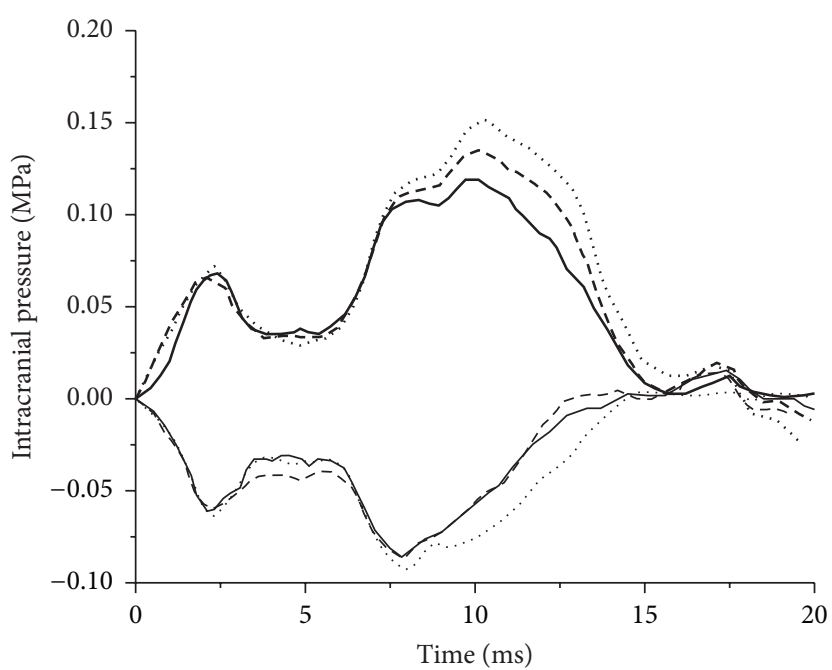

$\begin{aligned}-K & =21.9 \mathrm{MPa}, \text { coup } \\ ---K & =219 \mathrm{MPa}, \text { coup } \\ \ldots \ldots K & =2190 \mathrm{MPa}, \text { coup }\end{aligned}$

Figure 4: The intracranial pressure time histories with different $K$ values.

modulus $K$ on intracranial pressure. The results of Ex_1, Ex_6, and Ex_7 are shown in Figure 4 for the intracranial pressure time histories with different $K$ values. It shows that both coup pressure and contrecoup pressures decrease with lower $K$ values. When $K$ value is $21.9 \mathrm{MPa}$, the peak coup pressure reaches $117.1 \mathrm{kPa}$ and peak contrecoup pressure is $-88.1 \mathrm{kPa}$. The peak coup pressure increases to $159.8 \mathrm{kPa}$ and peak contrecoup pressure is $-97.2 \mathrm{kPa}$, when $K$ value increases to $2190 \mathrm{MPa}$. The decrease of bulk modulus $K$ values means that the hydrostatic pressure decreases in that brain tissue. As a result, the brain tissue of the impact side deforms more easily under the same loading conditions, which results in a lower coup pressure accordingly.

3.1.2. Shear Stress and Shear Strain. The peak shear stress increases while shear strain decreases with the increase of $K$ value. The peak shear stress increases from $13.7 \mathrm{kPa}$ to $17.9 \mathrm{kPa}$ when $K$ value increases from 21.9 MPa to $2190 \mathrm{MPa}$. However, the shear strain decreases sharply from 0.6 to 0.1 . The maximum shear stress occurs at dorsal pontine of brain stem when $K$ value is $21.9 \mathrm{MPa}$ and $219 \mathrm{MPa}$, and it occurs at the dorsal midbrain region of brain stem when $K$ value is $2190 \mathrm{MPa}$. While the maximum shear strain occurs at the lobe of cerebrum parietal cortex in impact side when $K$ value is 21.9 $\mathrm{MPa}$, it occurs at ventrolateral pons of brain stem when $K$ value is $219 \mathrm{MPa}$ and $2190 \mathrm{MPa}$. The results mean that location of maximum shear stress is not the same as that of maximum shear strain.

\subsection{Intracranial Response with Different G Values}

3.2.1. Intracranial Pressure. The absolute values of coup and contrecoup pressure rise with the increase of $G$ value as shown in Figure 5, which is plotted from the results of

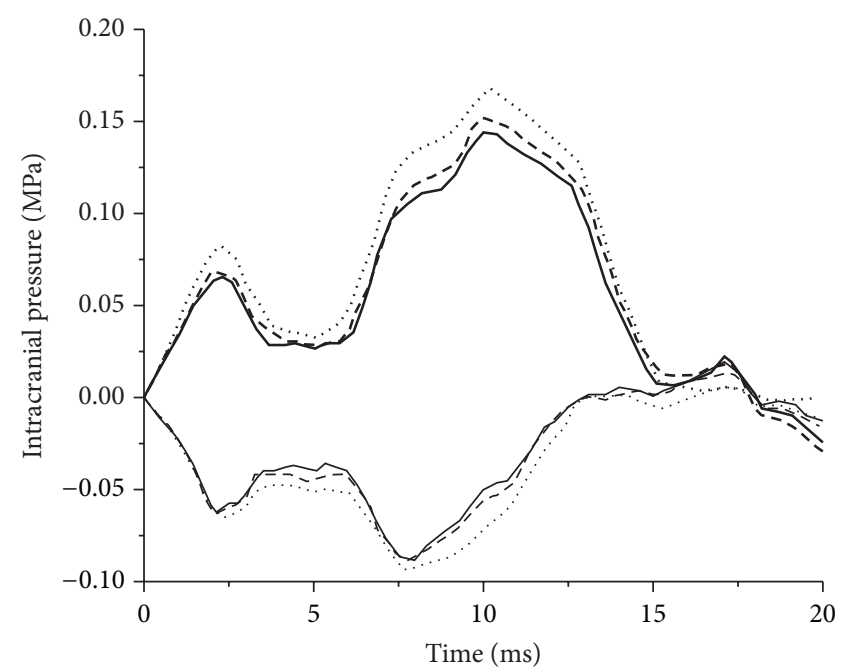

$$
\begin{array}{ll}
-G \text { value decreased } 10 \text { times, coup } & -G \text { value decreased } \\
---G \text { value, coup } & 10 \text { times, contrecoup } \\
\ldots . . . G \text { value increased } 10 \text { times, coup } & --G \text { value, contrecoup } \\
& \ldots . . G \text { value increased } \\
& 10 \text { times, contrecoup }
\end{array}
$$

FIGURE 5: Intracranial pressure time histories with different $G$ values.

baseline, Ex_1, and Ex_2 experiments. The coup pressure increases from $155.1 \mathrm{kPa}$ to $180.8 \mathrm{kPa}$ while contrecoup pressure increases from $-93.4 \mathrm{kPa}$ to $-100.5 \mathrm{kPa}$ when $G_{0}$ value increases from $4.9 \mathrm{kPa}$ to $490 \mathrm{kPa}$ and $G_{\infty}$ value increases from $1.62 \mathrm{kPa}$ to $162 \mathrm{kPa}$.

3.2.2. Shear Stress and Shear Strain. The impact direction of head in the simulation is not the same as the normal direction of engine hood surface. Therefore, the resultant head acceleration includes not only linear acceleration but also rotational acceleration during the impact process, which can lead to shear effect on brain tissues. Zhang et al. suggested that the probability of mild traumatic brain injury could be $50 \%$ when shear stress reaches $0.0078 \mathrm{MPa}$, and probability could be $80 \%$ when it exceeds $0.01 \mathrm{MPa}$ [25]. If shear stress with $0.01 \mathrm{MPa}$ is set as the injury criteria when evaluating the simulation results of brain tissues, it can be seen that the shear stress is higher than $0.01 \mathrm{MPa}$ with an increase of $G$ value by 10 times as shown in Figure 6(c). This indicates that risk of mild traumatic brain injury area is high. All the shear stresses illustrated in Figures 6(a) and 6(b) are less than $0.01 \mathrm{MPa}$ when decreasing $G$ value by 10 times, which indicates a lower risk of mild traumatic brain injury for brain tissues. If shear stress with $0.0078 \mathrm{MPa}$ is set as injury criteria, injury risk occurs at mesencephalic aqueduct area of ventricle with 10 times lower $G$ value (Figure 6(a)). Obviously, the risk of brain tissue injury increases with the increase of $G$ value.

Likewise, peak shear stress also increases continuously with the increase of $G$ value. When the $G$ value is reduced by 10 times, the peak shear stress is $0.011 \mathrm{MPa}$ and occurs at the dorsal pontine of brain stem. When the $G$ value increases to 10 times, the peak shear stress reaches $0.054 \mathrm{MPa}$ and occurs at the lateral parietal cortex in the impact side. Therefore, both 

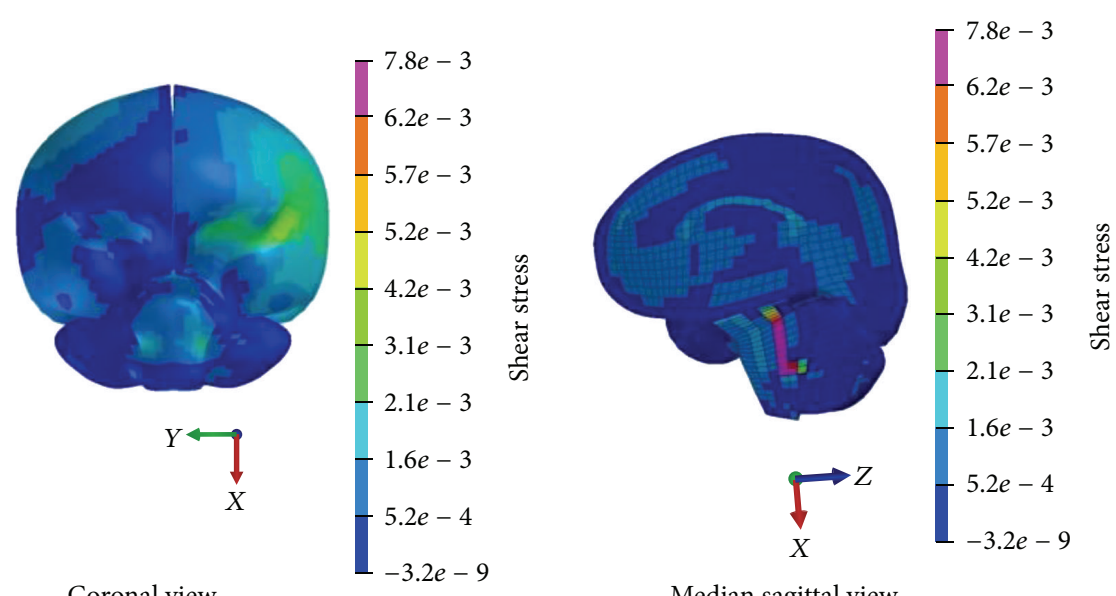

Median sagittal view

(a) $G_{0}=4.9 \mathrm{kPa}, G_{\infty}=1.62 \mathrm{kPa}$ in Ex_1 experiment

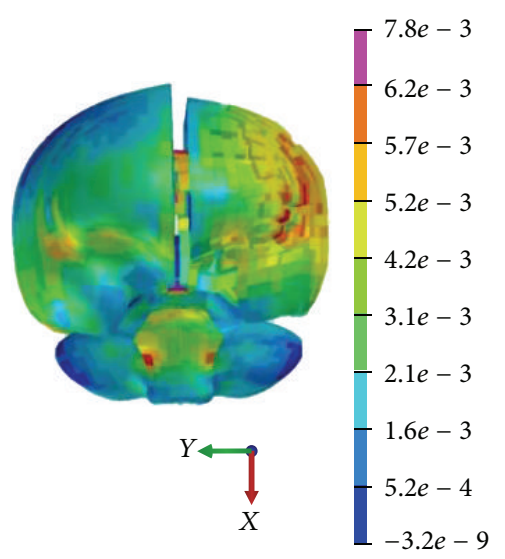

Coronal view

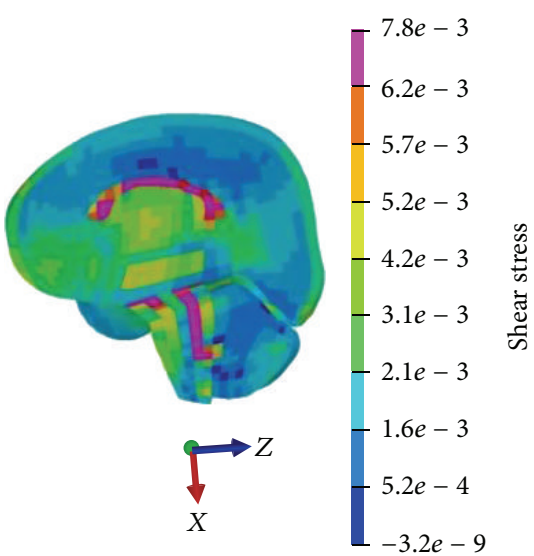

Median sagittal view

(b) $G_{0}=49 \mathrm{kPa}, G_{\infty}=16.2 \mathrm{kPa}$ in base experiment

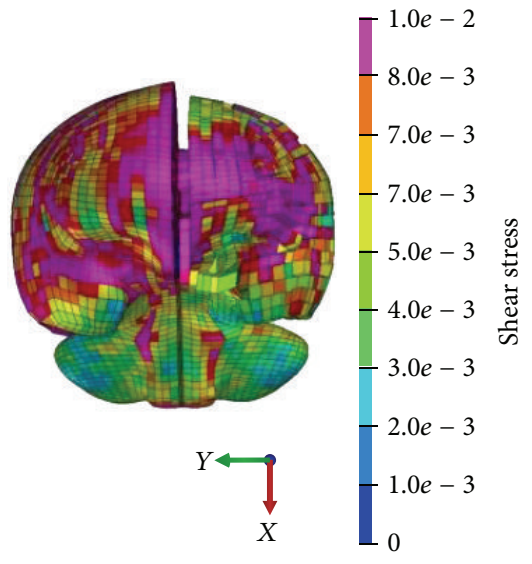

Coronal view

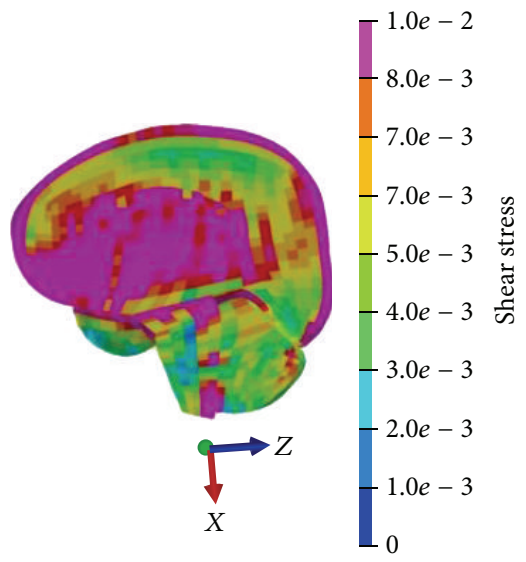

Median sagittal view

(c) $G_{0}=490 \mathrm{kPa}, G_{\infty}=162 \mathrm{kPa}$ in Ex_2 experiment

FIgURE 6: Shear stress distribution with different $G$ values.

peak values and peak areas of shear stress constantly vary with the increase of $G$ value.

However, shear strain of brain tissues decreases with the increase of $G$ value (Figure 7), whose trend is opposite to that of shear stress. The peak shear strain decreases from 0.20 to 0.012 when the $G_{0}$ value increases from $4.9 \mathrm{kPa}$ to $490 \mathrm{kPa}$ and $G_{\infty}$ value increases from $1.62 \mathrm{kPa}$ to $162 \mathrm{kPa}$. Also, the peak shear strain area occurs at temporal lobe with the 10 times 


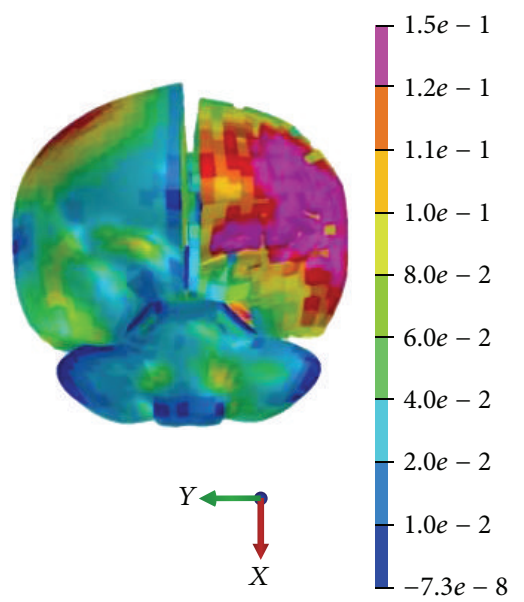

Coronal view

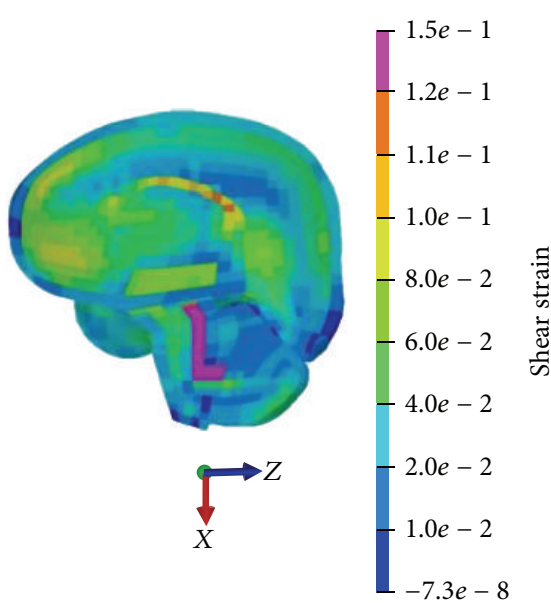

Median sagittal view

(a) $G_{0}=4.9 \mathrm{kPa}, G_{\infty}=1.62 \mathrm{kPa}$ in Ex_1 experiment

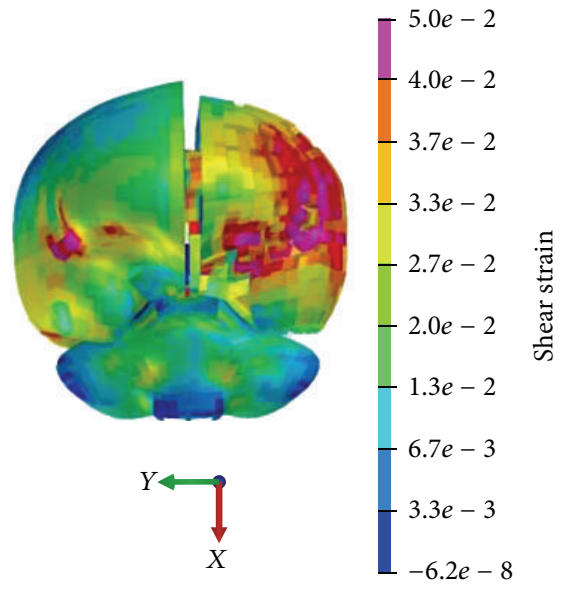

Coronal view

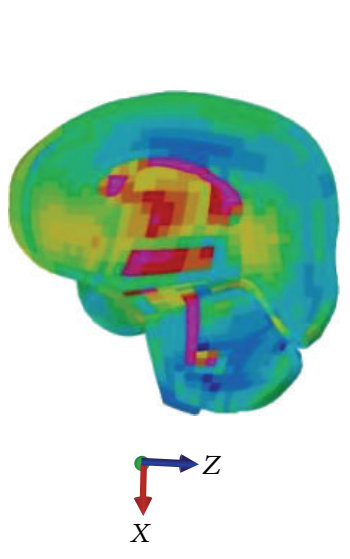

Median sagittal view

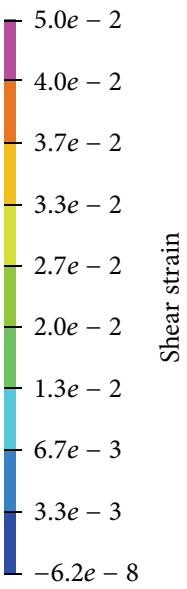

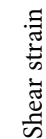

(b) $G_{0}=49 \mathrm{kPa}, G_{\infty}=16.2 \mathrm{kPa}$ in base experiment

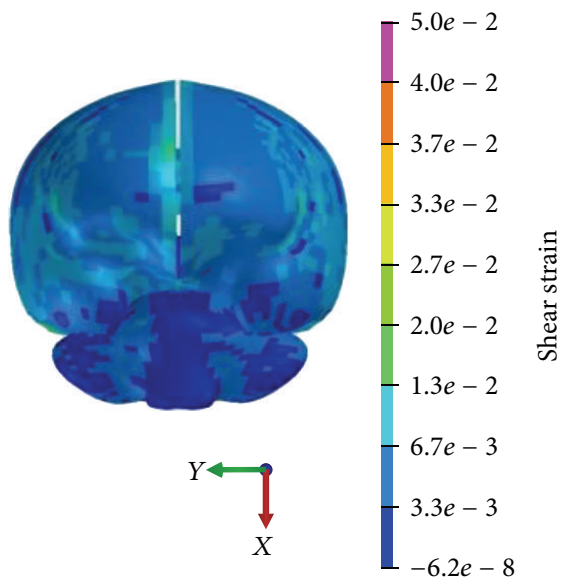

Coronal view

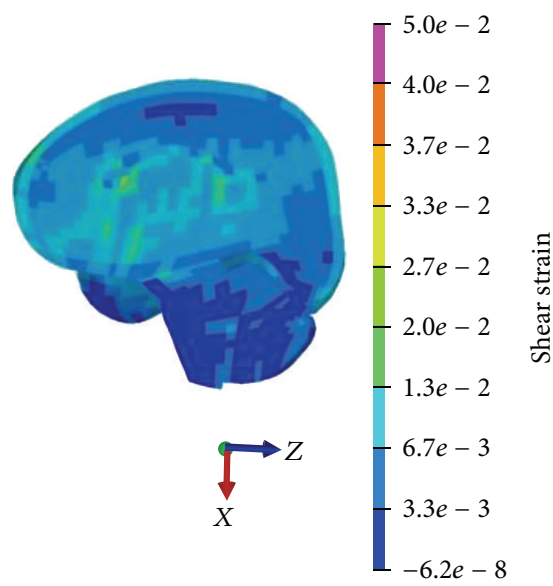

Median sagittal view

(c) $G_{0}=490 \mathrm{kPa}, G_{\infty}=162 \mathrm{kPa}$ in Ex_2 experiment

FIGURE 7: Shear strain distribution with different $G$ values. 


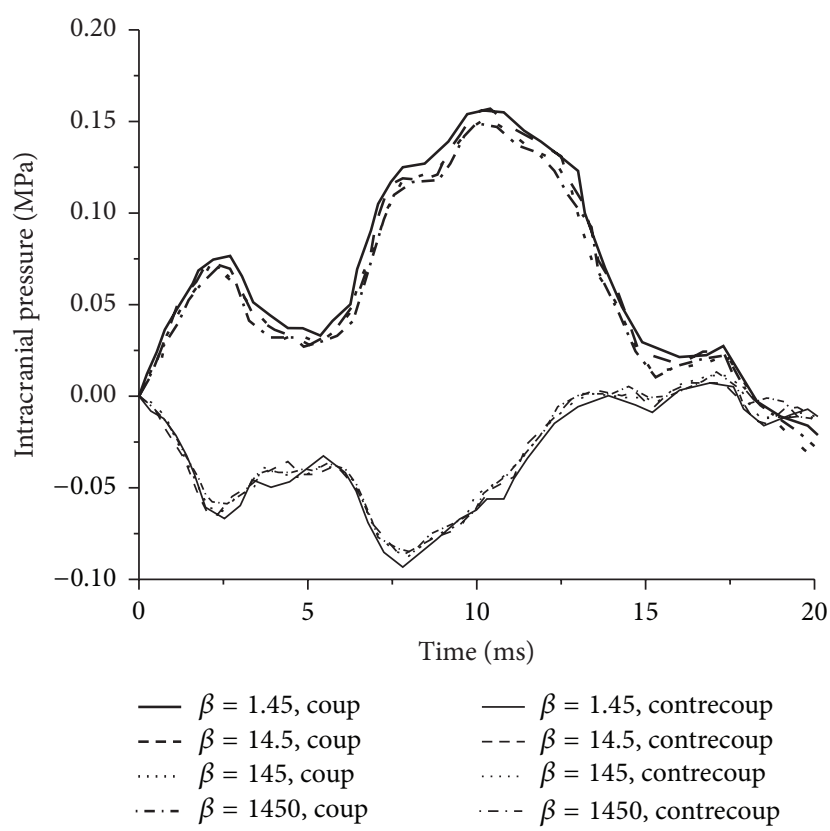

FIGURE 8: Intracranial pressure time histories with different $\beta$ values.

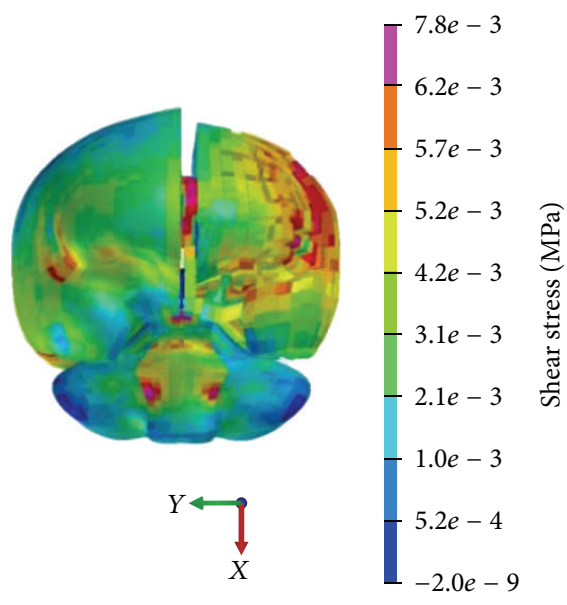

(a) $\beta=1.45$

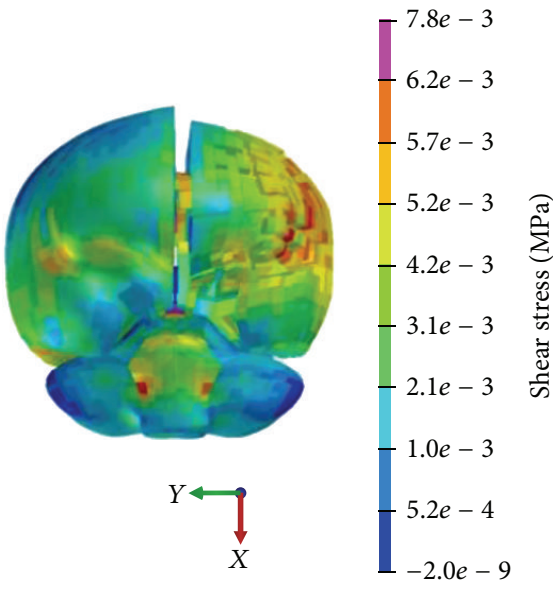

(c) $\beta=145$

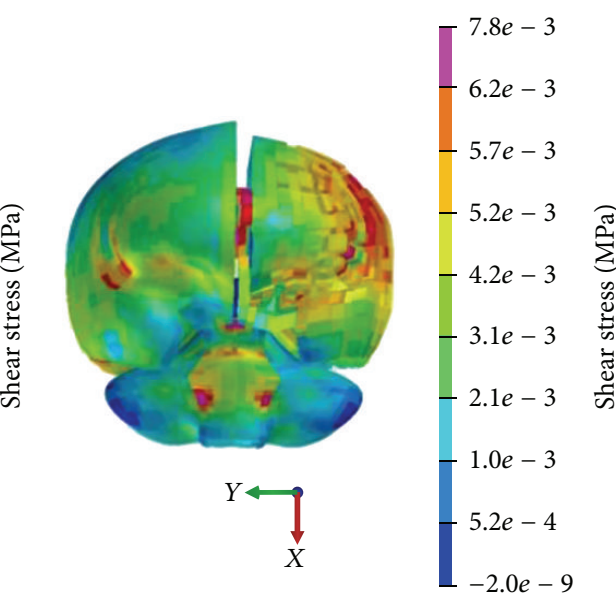

(b) $\beta=14.5$

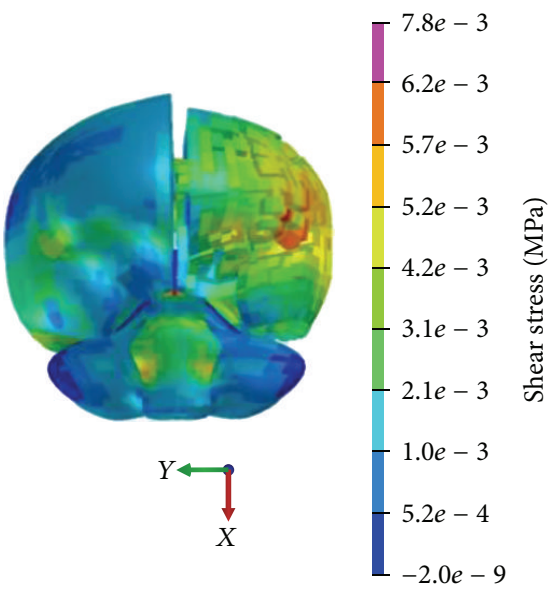

(d) $\beta=1450$

FIGURE 9: Brain shear stress distribution with different $\beta$ value (coronal view). 


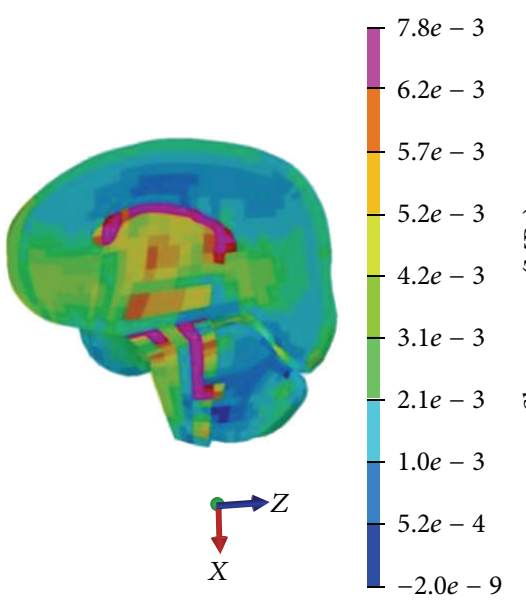

(a) $\beta=1.45$

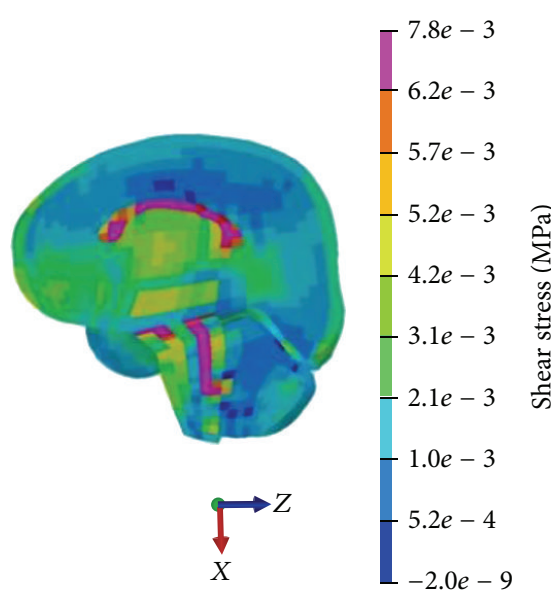

(c) $\beta=145$

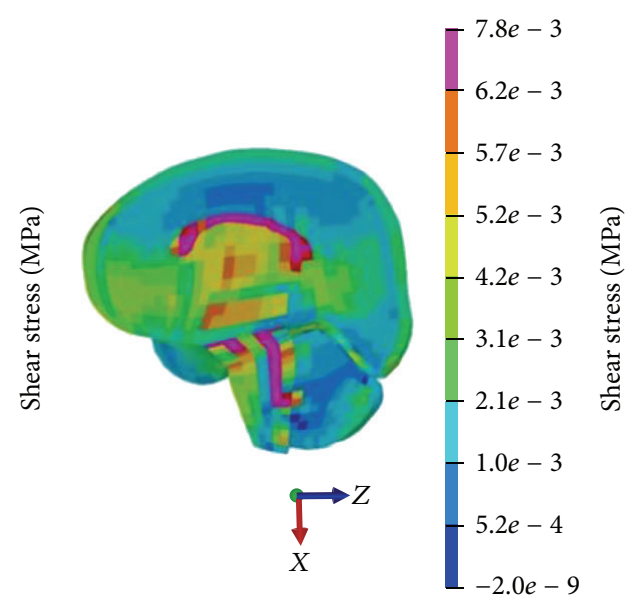

(b) $\beta=14.5$

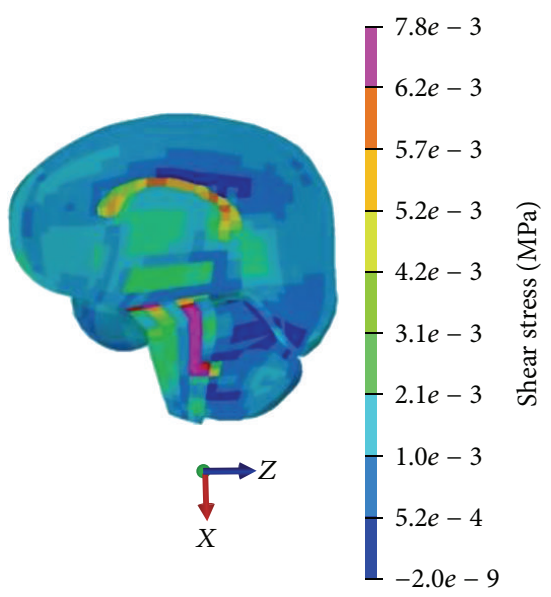

(d) $\beta=1450$

FIGURE 10: Brain shear stress distribution with different $\beta$ values (sagittal view).

decreased $G$ value while it happened at corpus callosum in impact side with the 10 times increased $G$ value.

\subsection{Intracranial Response with Different $\beta$ Values}

3.3.1. Intracranial Pressure. Simulation results in Figure 8 from base, Ex_3, Ex_4, and Ex_5 experiments show that intracranial pressure time history curves with different decay coefficient $\beta$ values almost overlap each other, which indicates that $\beta$ variation has no effect on intracranial pressure. The peak coup pressures with different $\beta$ values are $0.159 \mathrm{MPa}$.

3.3.2. Shear Stress and Shear Strain. According to Zhang's shear stress injury criteria with $0.0078 \mathrm{MPa}$ [25], brain shear stress distribution with different $\beta$ values is shown in Figures 9 and 10. It can be seen that the injury risk area, especially at the lobe of cerebrum parietal cortex, ventrolateral pons of brain stem, and corpus callosum on impact side, decreases with the increase of $\beta$ value.

The upper limit values of brain shear strain with different $\beta$ values were investigated in order to obtain the same high strain area at the cerebral cortex in the impact side. In Figure 11, it can be seen that the upper limit shear strain value is 0.055 with $\beta$ value of $1.45 \mathrm{~s}^{-1}$ while it is 0.12 with $\beta$ value of $1450 \mathrm{~s}^{-1}$.

Though $\beta$ variation has no effect on intracranial pressure, it really has large effect on shear stress and shear strain. The brain injury risk is higher when the $\beta$ value is $1450 \mathrm{~s}^{-1}$.

\section{Conclusions}

The finite element head model of a child with detailed anatomical structures was established based on CT images of a 6-year-old healthy child head. According to Euro-NCAP testing regulation, impact simulation experiments between the child head model and engine hood were studied. The influence of brain mechanical properties on the intracranial response was analyzed systematically through a comprehensive parametric study.

Intracranial pressure and shear stress of brain tissues increase with the increase of bulk modulus $K$ while shear strain decreases. Likewise, values of peak shear stress and 


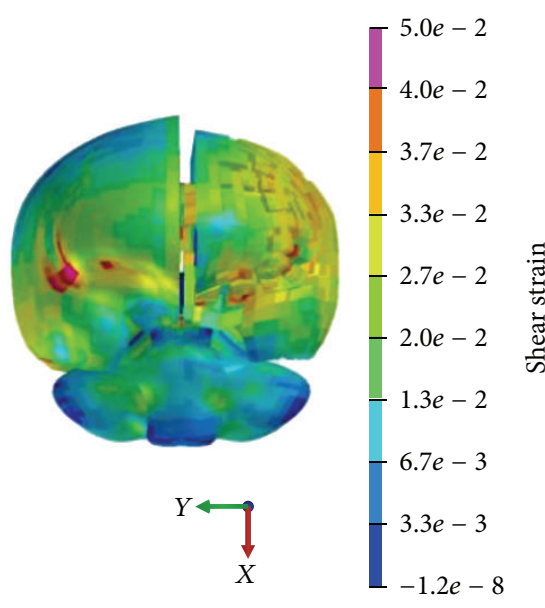

(a) $\beta=1.45$

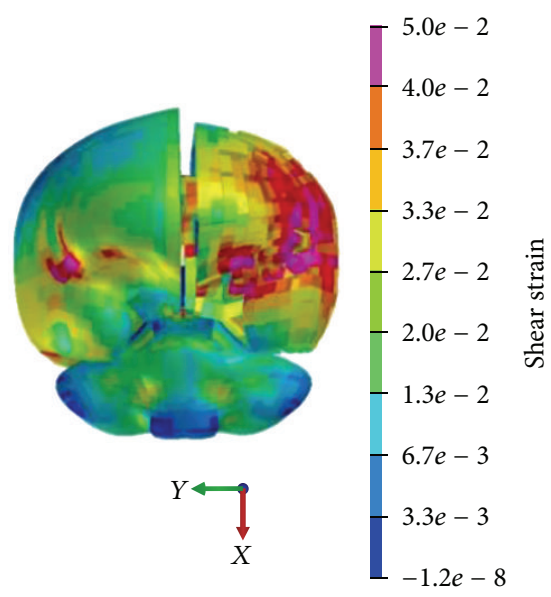

(c) $\beta=145$

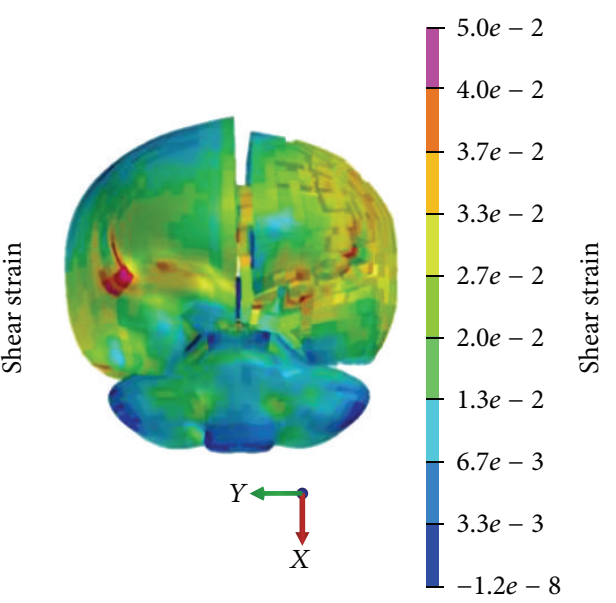

(b) $\beta=14.5$

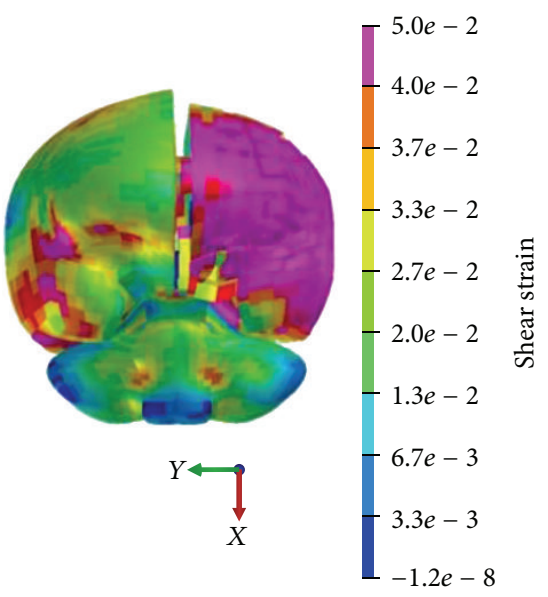

(d) $\beta=1450$

FIGURE 11: Brain shear strain distribution with different $\beta$ value.

shear strain are both different with the variation of the $K$ values.

The effects of shear modulus $G$ on the variation of intracranial pressure, shear stress, and shear strain have the same trend as the bulk modulus $K$.

As for decay coefficient $\beta$, various $\beta$ values almost have no influence on intracranial pressure. However, the peak shear stress decreases and shear strain increases with greater $\beta$ value.

\section{Conflict of Interests}

The authors declare that there is no conflict of interests regarding the publication of this paper.

\section{Acknowledgment}

This work was supported by the National Natural Science Foundation of China (81201015, 81371360, and 81471274).

\section{References}

[1] D. Viano, H. von Holst, and E. Gordon, "Serious brain injury from traffic-related causes: priorities for primary prevention," Accident Analysis and Prevention, vol. 29, no. 6, pp. 811-816, 1997.

[2] J. Ouyang, W. Zhao, Y. Xu, W. Chen, and S. Zhong, “Thoracic impact testing of pediatric cadaveric subjects," The Journal of Trauma, vol. 61, no. 6, pp. 1492-1500, 2006.

[3] T. J. Horgan and M. D. Gilchrist, "The creation of threedimensional finite element models for simulating head impact biomechanics," International Journal of Crashworthiness, vol. 8, no. 4, pp. 353-366, 2003.

[4] S. Ji, W. Zhao, Z. Li, and T. W. McAllister, "Head impact accelerations for brain strain-related responses in contact sports: a model-based investigation," Biomechanics and Modeling in Mechanobiology, vol. 13, no. 5, pp. 1121-1136, 2014.

[5] Z. Li, J. Hu, M. P. Reed et al., "Development, validation, and application of a parametric pediatric head finite element model for impact simulations," Annals of Biomedical Engineering, vol. 39, no. 12, pp. 2984-2997, 2011. 
[6] H. Mao, L. Zhang, B. Jiang et al., "Development of a finite element human head model partially validated with thirty five experimental cases," Journal of Biomechanical Engineering, vol. 135, no. 11, Article ID 111002, 15 pages, 2013.

[7] W. Zhao, S. J. Ruan, and S. Ji, "Brain pressure responses in translational head impact: a dimensional analysis and a further computational study," Biomechanics and Modeling in Mechanobiology, vol. 14, no. 4, pp. 753-766, 2015.

[8] S. Roth, J.-S. Raul, B. Ludes, and R. Willinger, "Finite element analysis of impact and shaking inflicted to a child," International Journal of Legal Medicine, vol. 121, no. 3, pp. 223-228, 2007.

[9] S. Roth, J.-S. Raul, J. Ruan, and R. Willinger, "Limitation of scaling methods in child head finite element modelling," International Journal of Vehicle Safety, vol. 2, no. 4, pp. 404-421, 2007.

[10] S. Roth, J.-S. Raul, and R. Willinger, "Finite element modelling of paediatric head impact: global validation against experimental data," Computer Methods and Programs in Biomedicine, vol. 99, no. 1, pp. 25-33, 2010.

[11] S. Roth, J. Vappou, J.-S. Raul, and R. Willinger, "Child head injury criteria investigation through numerical simulation of real world trauma," Computer Methods and Programs in Biomedicine, vol. 93, no. 1, pp. 32-45, 2009.

[12] S.-J. Ruan, P.-D. Li, H.-Y. Li, and W. Zhao, "Development and validation of a 6-year-old child finite element head model," Chinese Journal of Biomedical Engineering, vol. 31, no. 4, pp. 502506, 2012 (Chinese).

[13] L. B. Cao, Z. Zhou, B. H. Jiang et al., "Development and validation of a 6-year-old child finite element head model," Chinese Journal of biomechanical engineering, vol. 33, no. 1, pp. 63-70, 2014 (Chinese).

[14] K. L. Thibault and S. S. Margulies, "Age-dependent material properties of the porcine cerebrum: effect on pediatric inertial head injury criteria," Journal of Biomechanics, vol. 31, no. 12, pp. 1119-1126, 1998.

[15] S. Chatelin, J. Vappou, S. Roth, J. S. Raul, and R. Willinger, "Towards child versus adult brain mechanical properties," Journal of the Mechanical Behavior of Biomedical Materials, vol. 6, pp. 166-173, 2012.

[16] S. Nicolle, M. Lounis, R. Willinger, and J.-F. Palierne, "Shear linear behavior of brain tissue over a large frequency range," Biorheology, vol. 42, no. 3, pp. 209-223, 2005.

[17] L. Z. Shuck and S. H. Advani, "Rheological response of human brain tissue in shearing," Journal of Basic Engineering, vol. 94, no. 4, pp. 905-911, 1972.

[18] E. S. Lee, A large-strain, transient-dynamic analysis of head injury problems by the finite element method [Ph.D. thesis], Georgia Institute of Technology, Atlanta, Georgia, 1990.

[19] F. DiMasi, J. H. Marcus, and R. H. Eppinger, "3-D anatomic brain for relating cortical strains to automobile crash loading," in Proceedings of the 13th International Technical Conference on Experimental Safety Vehicles, Paris, France, November 1991.

[20] J. Ruan, Impact biomechanics of head injury by mathematical modeling [Ph.D. dissertation], Waye State University, Detroit, Mich, USA, 1994.

[21] W. Zhao, S. J. Ruan, H. Y. Li, S. Cui, L. He, and J. Li, "Development and validation of a 5 th percentile human head finite element model based on the Chinese population," International Journal of Vehicle Safety, vol. 6, no. 2, pp. 91-109, 2012.

[22] X. N. Li, Finite element simulation and impact analysis of pedestrian head injury mechanisms for children [M.S. thesis], Tianjin University of Science and Technology, 2014 (Chinese).
[23] J. Dobbing, The Later Development of the Brain and Its Vulnerability, Scientific Foundations of Paediatrics, Heinemann Medical, London, UK, 1981.

[24] http://www.euroncap.com/en/for-engineers/proto-cols/pedestrian-protection/.

[25] L. Y. Zhang, K. H. Yang, and A. I. King, "A proposed injury threshold for mild traumatic brain injury," Journal of Biomechanical Engineering, vol. 126, no. 2, pp. 226-236, 2004. 


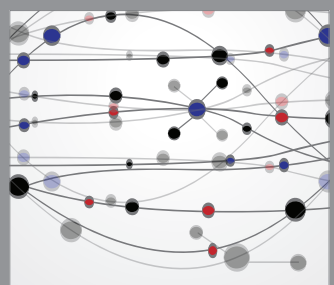

The Scientific World Journal
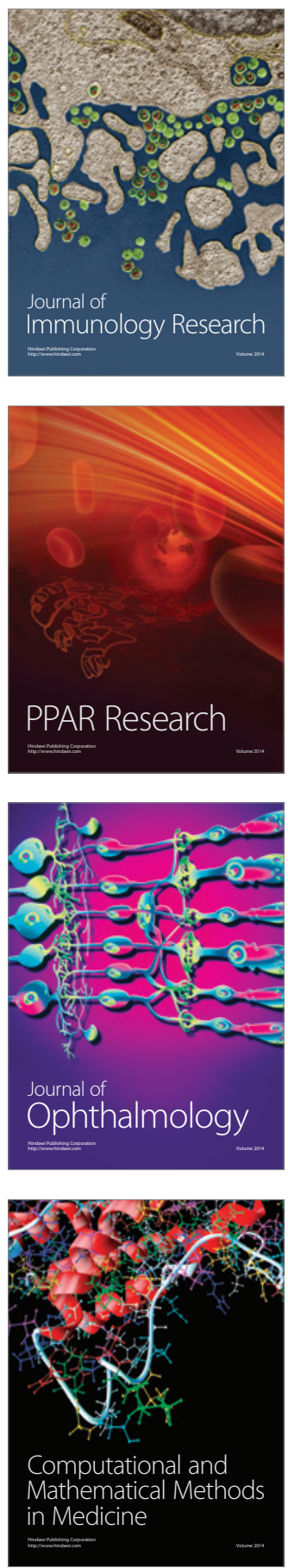

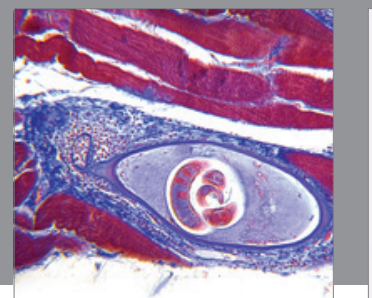

Gastroenterology

Research and Practice
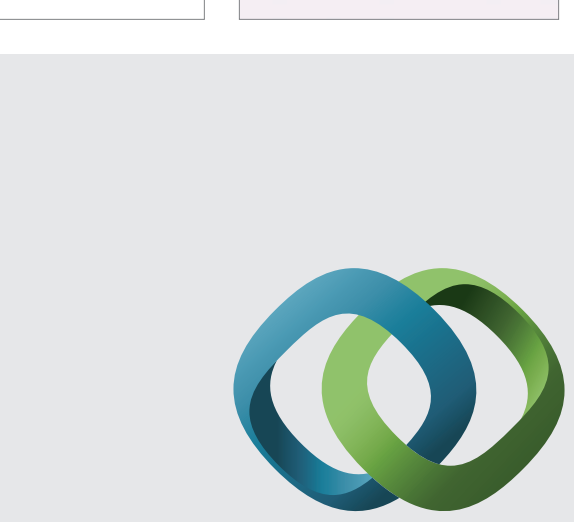

\section{Hindawi}

Submit your manuscripts at

http://www.hindawi.com
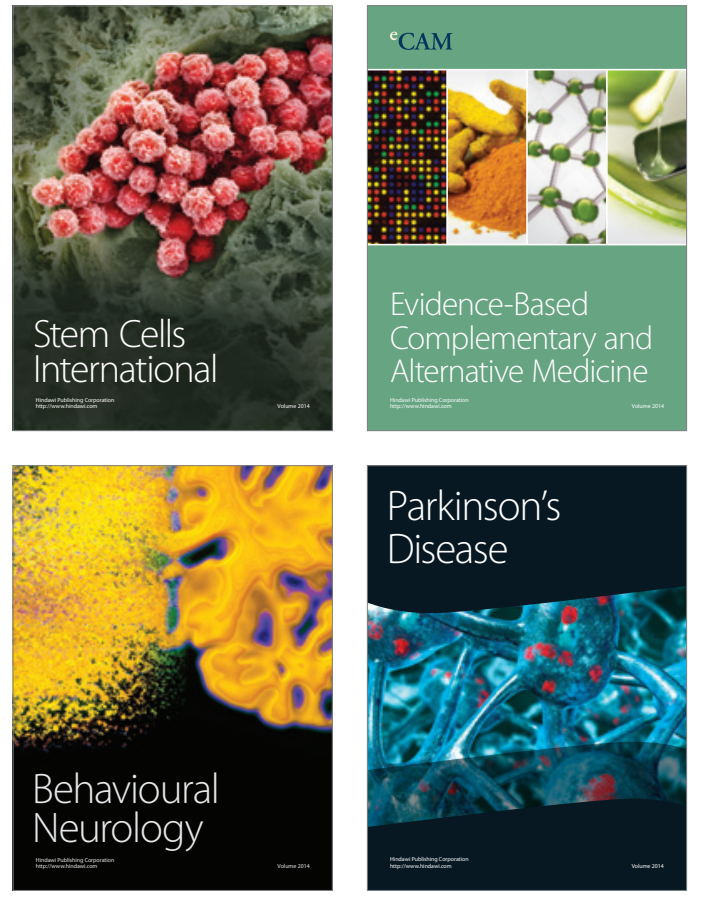
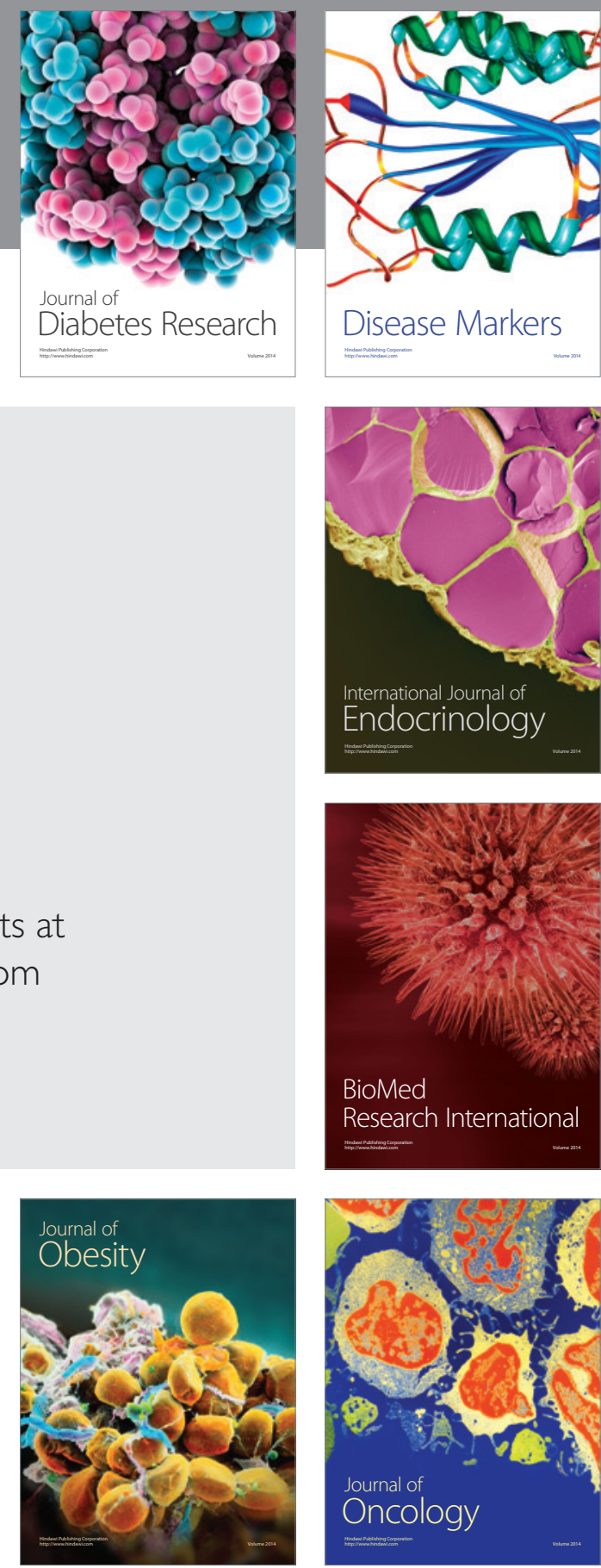

Disease Markers
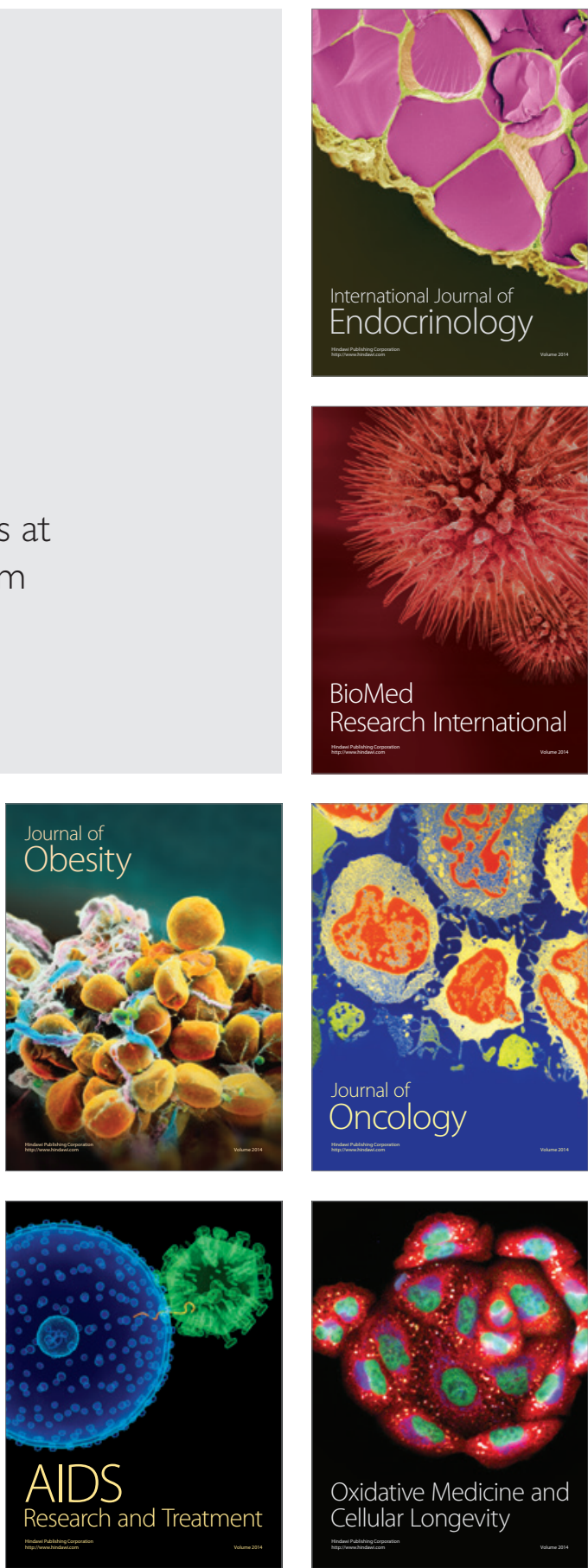